\title{
5.I ¡Más que una promesa, un compromiso!
}

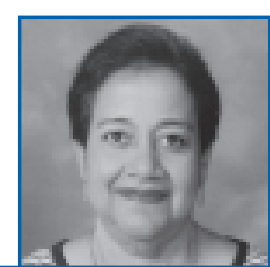

por Rosario Bisonó

\section{Resumen}

Reflexión que la profesora Rosario Bisonó, de la carrera de Ingeniería Industrial, en Santiago, expuso durante clases a sus compañeros de la Especialidad en Pedagogía Universitaria. Este programa académico es ofrecido periódicamente por la PUCMM a sus profesores.

En mis años de juventud (iy ha llovido mucho desde entonces!) en múltiples ocasiones escuché a mis padres, que no eran profesionales universitarios, quejarse del comportamiento de los jóvenes y decir: "-A esos muchachos/as, la Universidad les pasó por encima." No había una coherencia entre la imagen que ellos tenían de un universitario y el testimonio de vida que evidenciaban.

En mi anterior trabajo, algunos gerentes se quejaban sobre el dilema entre la formación académica y los resultados en la práctica profesional. En mi condición de responsable de la gestión humana, debía programar actividades de desarrollo y siempre encontraba obstáculos para permitir que los empleados participaran. La resistencia venía acompañada de esta frase: "-Tantos cursos y siempre siguen iguales."

En ambas situaciones, en mi casa y en el trabajo, la máxima popular "el hábito no hace al monje" encaja perfectamente. Si no existe un firme convencimiento de que necesitamos y podemos crecer y cambiar, los esfuerzos que una persona externa pueda hacer por nosotros son en vano.
Esta Especialidad en Pedagogía Universitaria me ha permitido tomar distancia de mí misma y ver cómo actúo y qué me mueve a hacer una cosa $u$ otra. He reflexionado sobre mi estilo, he cuestionado mis acciones. He abierto ventanas de crecimiento profesional y he degustado la insatisfacción que me invita cada día a superarme.

Mis metas docentes siempre estuvieron impregnadas de una gran preocupación por la calidad de las acciones que ejecuto, guiadas por un sentido netamente técnico, sin llegar a ser deshumanizadas. Los años, la experiencia, los intereses personales, han contribuido a modificar esas características tan propias. Sin embargo, es a través de la Especialidad que he logrado una concepción más humana de mis estudiantes, poder verlos en su dimensión de "personas", con sus fortalezas y debilidades, con sus potencialidades y limitaciones. No son robots a quien doy una instrucción y responden de la manera que yo quiero. Hay una individualidad y existen unas diferencias que debo tomar en cuenta y hasta alegrarme de que así sea, pues en la diversidad está la verdadera riqueza de los grupos humanos.

Definitivamente, las lecturas que tuve que hacer en el proceso de fundamentación del Proyecto Pedagógico me cautivaron y movilizaron sentimientos muy particulares que fundamentan mi transformación profesional. Al principio yo estaba reacia a leer sobre temas que entendía que no eran para mí, pero hoy es diferente.

Esta ocasión es propicia para decirme a mí misma, a mis padres (aún en su ausencia

\footnotetext{
1 Ingeniera Industrial. Profesora de Tiempo Completo de la Facultad de Ciencias de la Ingeniería. Participante de la segunda Cohorte de la Especialidad en Pedagogía Universitaria.
}

\section{Cuaderno de Pedagogía Universitaria}


material) y a aquellos que fueron mis compañeros de trabajo que hay aquí una persona a quien los conocimientos no "le han pasado por arriba". Una persona que hace esfuerzos conscientes para superar las debilidades, que ha robustecido su vocación pero sobretodo su voluntad, que ha tomado conciencia de que debe mejorar . Esa persona soy yo y a pesar del cansancio de los años, aún creo en la docencia y me quedan bríos y e ilusión de entregar lo mejor de mí misma a mis estudiantes.

Más que un proyecto académico, estoy reescribiendo mi propio proyecto de vida y abriendo senderos para que otros también construyan el suyo. Así será porque así lo he decidido, así lo acepto y comparto con aquéllos que tienen que ver con esta Especialidad.

Finalizo con una frase que es una invitación a poner en práctica lo que estamos aprendiendo a base de esfuerzo y hasta con ciertos matices de moderada resistencia:

“El conocimiento pedagógico no es algo que se aprende cursando estudios docentes, el sitio donde se aprende a ser maestro es la escuela, el aula."

-Cecilia Bixio, Enseñar a aprender (2005). 